\title{
Mendicidad ajena como modalidad del delito de trata de personas. Caso embera-chamí
}

\section{Forced begging as a form of the crime of trafficking in persons. Embera-chamí case}

\author{
Laura Melissa Álvarez \\ Laura Daniela Buitrago Calvo ${ }^{* * *}$ \\ Gerson Fajardo Guevara ${ }^{* * *}$
}

Fecha de recepción: 30 de octubre de 2018

Fecha de aprobación: 30 de noviembre de 2018

\section{RESUMEN}

La lucha contra la trata de personas como problemática mundial se ha convertido en prioridad para todos los países, dada su grave vulneración y afectación a los derechos humanos de especial protección. Dentro de sus modalidades de acción se encuentra la mendicidad

* El artículo surge en el marco de la Maestría en Derecho Penal de la Universidad Libre Seccional PereiraColombia, a partir de una investigación denominada "Mendicidad ajena como modalidad del delito de trata de personas de niños, niñas y adolescentes de la comunidad embera-chamí que se desplazan a la ciudad de Pereira, periodo 2014-2015”, del grupo de investigación Estado, Derecho y Sociedad en la línea Sistema Penal Acusatorio. Citar como Álvarez, L., Buitrago Calvo, L. y Fajardo Guevara, G. (2019). Mendicidad ajena como modalidad del delito de trata de personas. Caso embera-chamí. Via Inveniendi et Iudicandi, 14(1), 129-156. Doi: https://doi.org/10.15332/s1909-0528.2019.0001.05

** Abogada. Magíster en Derecho Penal, Universidad Libre Seccional Pereira. (Pereira, Colombia). lauramalvarez29@gmail.com

*** Abogada. Magíster en Derecho Penal, Universidad Libre Seccional Pereira. (Pereira, Colombia). daniela1279li@hotmail.com

**** Coronel y abogado. Magíster en Derecho Penal, Universidad Libre Seccional Pereira. (Pereira, Colombia). gersonfajardo_8@hotmail.com 


\section{VIeI Revista Virtual}

Via Inveniendi et Iudicandi

ajena, en la cual la persona, una vez puesta en condiciones indignas, es obligada a pedir limosna con el fin de obtener un beneficio para un tercero, lo que constituye un modo de explotación laboral al cual son más propensas la infancia y la adolescencia, sobre todo de comunidades indígenas.

Palabras clave: mendicidad ajena, infancia, adolescencia, jurisdicción indígena, imputación penal.

\section{Abstract}

The fight against trafficking in persons as a global problem has become a priority for all countries, given their serious violation and impact on human rights of special protection. Within its modalities of action is the begging of others, in which the person, once placed in unworthy conditions, is obliged to ask for alms in order to obtain a benefit for a third party, which constitutes a mode of labor exploitation to which are more prone to childhood and adolescence, especially of indigenous communities.

Keywords: Begging others, childhood, teenagers, indigenous jurisdiction, criminal charges. 
Laura Melissa Álvarez, Laura Daniela Calvo, Gerson Fajardo Guevara

\section{INTRODUCCIÓN}

Una de las mayores problemáticas del mundo moderno a nivel criminológico está dada por el tipo penal de trata de personas. De acuerdo a informes presentados por la Organización de las Naciones Unidas contra la Droga y el Delito (UNODC) es el tercer delito de mayor ocurrencia, después del tráfico de estupefacientes y el de armas. La legislación colombiana la define en el Código Penal, en su artículo 188: "El que capte, traslade, acoja o reciba a una persona, dentro del territorio nacional o hacia el exterior, con fines de explotación, incurrirá en prisión” (Ley 599 de 2000). $\mathrm{Al}$ respecto es importante recordar que, al constituirse Colombia como Estado social de derecho, asume entre sus objetivos la protección al débil jurídico (Manzo, 2018).

La complejidad que encierra la definición misma del concepto de trata de personas no solo deviene de la inclusión de distintos verbos rectores, sino también de las variadas modalidades asociadas a esta problemática: la explotación sexual, la explotación laboral, la mendicidad ajena, el matrimonio servil y el tráfico de órganos. En ese sentido, es importante precisar, de conformidad con Castro (2018), que la teoría jurídica trata de determinar afirmaciones generales y verificables sobre las normas jurídicas y su forma de afectación sobre la sociedad.

Es así como Meertens señala que

el comercio de seres humanos ha sido una práctica milenaria, cientos de hombres y mujeres fueron vendidos como esclavos, miles de personas fueron traídas desde América y Europa, muchos de ellos y ellas murieron en el trayecto, las mujeres fueron violadas, obligadas a servir en familias prestantes de la época, y a prostituirse. Esta situación no solo afectó a mujeres africanas, sino también a indígenas y europeas. (2009, p. 33)

Reducir al ser humano a un objeto y obtener un provecho económico de ello, en la actualidad en Colombia implica la comisión de una conducta punible, tipificada en el ya mencionado art. 188 del Código Penal: 
Trata de personas. [...] Para efectos de este artículo se entenderá por explotación el obtener provecho económico o cualquier otro beneficio para sí o para otra persona, mediante la explotación de la prostitución ajena u otras formas de explotación sexual, los trabajos o servicios forzados, la esclavitud o las prácticas análogas a la esclavitud, la servidumbre, la explotación de la mendicidad ajena. (Ley 599 de 2000)

Se tiene como propósito analizar la mendicidad ajena como modalidad del delito de trata de personas en niños, niñas y adolescentes indígenas pertenecientes a la comunidad embera-chamí, en el departamento de Risaralda (Colombia), atendiendo a la existencia de diversas jurisdicciones. Para ello se determinó como campo de estudio el municipio de Pereira (Risaralda) ${ }^{1}$ en un periodo comprendido entre 2014 y 2015. El problema se aborda a partir de un enfoque sociojurídico que permita establecer tanto las condiciones sociales que envuelven dicha conducta como la controversia existente entre la jurisdicción ordinaria y la jurisdicción especial indígena (JEI) en esta materia, que impiden o dificultan la respectiva imputación penal y la posterior judicialización del referido delito.

Entre las comunidades indígenas existentes en Colombia se encuentra la comunidad embera-chamí, que será protagonista del presente estudio porque se ha evidenciado, previa denuncia pública, un posible caso de trata de personas de dicha comunidad en las calles del municipio de Pereira (Colombia).

Para contextualizar un poco acerca de los embera-chamí se debe tener presente que

fue en sus orígenes un grupo nómada dedicado a la caza, la pesca y la recolección. Antes de que sus territorios fueran colonizados por los espańoles, tenían una íntima relación con la tierra, ya que la misma [sic] constituía la base de su existencia, reivindicando el usufructo de los recursos naturales para

1 Pereira es la capital del departamento de Risaralda, de la República de Colombia. Su estratégica localización central dentro de la región cafetera la ubica en el panorama económico nacional e internacional pues está unida vialmente con los tres centros urbanos más importantes del territorio nacional y tiene acceso a medios de comunicación internacionales tanto marítimos como aéreos (Alcaldía de Pereira, 2017). 
Laura Melissa Álvarez, Laura Daniela Calvo, Gerson Fajardo Guevara Mendicidad ajena como modalidad del delito de trata de personas. Caso embera-chamí

la supervivencia, con su servicio a la tierra, lo cual los hacía sentir parte de una comunidad. Esta comunidad conserva su lengua nativa, la cual pertenece a la familia lingüística chocó y habitan en su mayoría cerca al alto río San Juan en los municipios de Pueblo Rico y Mistrató del departamento de Risaralda. (Ministerio de Cultura, 2010)

Cuando se habla de trata de personas con fines de explotación laboral o trabajo forzado, se pueden considerar como tales fines: "Aquellas actividades relacionadas con la economía formal o informal como mendicidad, ventas callejeras, servicio doméstico, agricultura, pesquería, minería, construcción o trabajo en fábricas” (Meertens, 2009, p. 30).

La mendicidad, que a simple vista puede considerarse una actividad lícita propia de quien la asume al pedir limosna, puede encuadrase dentro de dicho tipo penal cuando existe explotación ajena; es decir, cuando el tratante, para su propio lucro, obliga a la víctima a pedir limosna.

Según lo establecido por la Organización Internacional de Migraciones (OIM, 2017), en la lucha contra la trata de personas en Colombia Pereira se ha identificado como uno de los principales municipios de origen de esta conducta delictiva. Al respecto, es importante resaltar que

el Sistema Interamericano de Derechos Humanos sufre en la actualidad una crisis financiera extrema. Ello en el plano de la protección de los derechos humanos puede generar consecuencias de gravedad, ya que este podría quedar sin la capacidad para poder cumplir con sus funciones. (Murcia, 2018, p. 55)

Lo que alarma aún más sobre la situación es que por la naturaleza de esta conducta delictiva los niños y niñas son más propensos a convertirse en sus víctimas. Meertens establece que "en niños y niñas la[s] modalidad[es] más frecuente[s son] la mendicidad, especialmente proveniente de comunidades indígenas, y la explotación laboral, especialmente de niños en las minas" (2009, p. 178). 
Así pues, en primera medida se hace una descripción del delito de trata de personas que permite contextualizar explícitamente su contenido y las modalidades en que se materializa, haciendo especial énfasis en la mendicidad ajena (Molina, 2016).

Posteriormente, se relacionan jurídicamente los aspectos fundamentales de la jurisdicción indígena determinando sus límites y alcances frente a la jurisdicción ordinaria. Inmediatamente después se evidencian las situaciones generadoras de un conflicto de competencias al momento de judicializar el delito de trata de personas en la modalidad de mendicidad ajena de niños, niñas y adolescentes indígenas de la comunidad embera-chamí, con base en los pronunciamientos de la Corte Constitucional al respecto.

Asimismo, se identifican las posibles causas por las cuales los niños, niñas y adolescentes indígenas de la comunidad embera-chamí son vinculados a la mendicidad ajena por sus padres y familiares mediante un desplazamiento hacia la ciudad de Pereira.

Además, se adelanta una exploración desde la perspectiva de la imputación penal, que arroja la configuración del delito de trata de personas por parte de las familias de la comunidad embera-chamí, con relación a sus niños y frente al ejercicio de la mendicidad ajena.

Finalmente, se indaga por la posibilidad de imputar el tipo penal de trata de personas, en la modalidad de mendicidad ajena, a las familias de niños, niñas y adolescentes indígenas de la comunidad embera-chamí que se encuentran en tales condiciones en Pereira por la responsabilidad de aquellas.

Esto permitirá conocer la aplicabilidad de la norma frente a un hecho social evidente, de modo que se establece si es viable judicializar esta conducta, teniendo en cuenta la protección constitucional de la cual gozan los indígenas dentro de su jurisdicción especial y las dificultades propias de los límites establecidos por el tribunal constitucional. 
Laura Melissa Álvarez, Laura Daniela Calvo, Gerson Fajardo Guevara Mendicidad ajena como modalidad del delito de trata de personas. Caso embera-chamí

\section{DEFINICIÓN Y PLANTEAMIENTO DEL PROBLEMA DE INVESTIGACIÓN}

Para empezar, cabe señalar que la comunidad indígena embera-chamí desde hace mucho tiempo se traslada a las calles de Pereira para que sus niños, nińas y adolescentes ejerzan allí la mendicidad.

Meertens (2009) establece que el $28 \%$ de casos de trata reportados en Antioquia y el Eje Cafetero tiene por víctimas a personas de comunidades indígenas, a pesar de su escasa presencia en estos territorios. Señala además que el $44 \%$ de estos casos corresponden a explotación de la mendicidad ajena.

Adicionalmente, al tratarse de niños, niñas y adolescentes indígenas, la situación se torna aún más compleja ya que en el artículo 7 de la Constitución Política de Colombia, "el Estado reconoce y protege la diversidad étnica y cultural de la nación".

Por lo anterior, al evidenciarse la posible existencia del tipo penal de trata de personas con fines de explotación de la mendicidad ajena ejercido sobre niños, niñas y adolescentes de la comunidad embera-chamí en la ciudad de Pereira, se señala que la situación ocurre fuera de su resguardo indígena y bajo la aplicación de la jurisdicción ordinaria (Quiroz, 2014). Por ello se plantea la pregunta: ¿Cuál es la razón para que desde la perspectiva de la imputación penal no se judicialice dicha conducta delictiva, a pesar de la existencia de todos los elementos exigidos por el tipo penal?

De acuerdo al interrogante anterior se planteó la tarea de establecer las condiciones actuales en las que se ha venido presentando la mendicidad ajena como modalidad del delito de trata de personas en niños, niñas y adolescentes de la comunidad embera-chamí.

Ahora bien, existen numerosas investigaciones sobre la trata de personas en la modalidad de explotación sexual (Huertas, Leyva, Lugo, Perdomo y Silvero, 2016), pero son pocas las que se ocupan de la mendicidad ajena en grupos indígenas. Particularmente, el caso embera-chamí (Risaralda) aquí planteado no se ha visibilizado en artículos, textos o investigaciones que identifiquen y profundicen sobre dicha problemática. 
La información más relevante encontrada se relaciona a continuación (tabla 1), analizando las tendencias encontradas, los temas tratados, las investigaciones y estudios en diferentes universidades y el aporte a la investigación sobre trata de personas y jurisdicción especial indígena (JEI).

Tabla 1. Estado del arte de la investigación sobre trata de personas y JEI

\begin{tabular}{|c|c|c|}
\hline $\begin{array}{c}\text { Título del } \\
\text { documento (tipo) }\end{array}$ & Autor & Aporte para la investigación \\
\hline $\begin{array}{l}\text { Metamorfosis de la } \\
\text { esclavitud. Manual } \\
\text { juridico sobre la } \\
\text { trata de personas } \\
\text { (libro) }\end{array}$ & $\begin{array}{l}\text { Victoria } \\
\text { Eugenia } \\
\text { Giraldo } \\
\text { Villa (dir.) }\end{array}$ & $\begin{array}{l}\text { "El texto ofrece un amplio desarrollo del delito de trata } \\
\text { de personas y de la forma de judicialización, resaltando las } \\
\text { falencias procedimentales dentro del sistema penal acusatorio } \\
\text { colombiano al momento de imputar y posteriormente } \\
\text { judicializar el delito" (Giraldo, 2008) }\end{array}$ \\
\hline
\end{tabular}

\begin{tabular}{|c|c|c|}
\hline $\begin{array}{l}\text { "Lucha contra la } \\
\text { trata de personas: } \\
\text { desafío para } \\
\text { Colombia en } \\
\text { el siglo XXI" } \\
\text { (artículo) }\end{array}$ & $\begin{array}{l}\text { María } \\
\text { Isabel } \\
\text { Henao Trip }\end{array}$ & $\begin{array}{l}\text { "El presente texto realiza un recuento de antecedentes } \\
\text { normativos, que permiten ver los orígenes de la trata de } \\
\text { personas, resaltándola como una problemática que desde } \\
\text { siglos anteriores no distinguía entre niños y mujeres de } \\
\text { diferentes razas, etnias y culturas. Se toma desde el precepto } \\
\text { normativo que el delito de trata de personas en el cual el bien } \\
\text { jurídico tutelado que resulta afectado es la autonomía, por } \\
\text { disposición del Código Penal, también lo son la libertad y la } \\
\text { integridad personal. De este modo ilustra y contextualiza la } \\
\text { judicialización del delito de trata de personas en sus distintas } \\
\text { modalidades, se encuentra concebido en la legislación } \\
\text { colombiana [y] está en un tipo penal complejo" (Henao, } \\
\text { 2008) }\end{array}$ \\
\hline
\end{tabular}

$\begin{array}{ll}\text { Estudio nacional } & \\ \text { exploratorio } & \\ \text { descriptivo del } & \text { Donny } \\ \text { fenómeno de trata } & \text { Meertens } \\ \text { depersonas en } & \\ \text { Colombia (libro) } & \end{array}$

\section{Estudio nacional}

exploratorio

descriptivo del

de personas en

Colombia (libro)
"El texto ofrece un amplio desarrollo del delito de trata de personas y de la forma de judicialización, resaltando las falencias procedimentales dentro del sistema penal acusatorio colombiano al momento de imputar y posteriormente judicializar el delito" (Giraldo, 2008)

"El presente texto realiza un recuento de antecedentes normativos, que permiten ver los orígenes de la trata de personas, resaltandola como una problemática que desde diferentes razas, etnias y culturas. Se toma desde el precepto normativo que el delito de trata de personas en el cual el bien disposición del Código Penal, también lo son la libertad y la integridad personal. De este modo ilustra y contextualiza la judicialización del delito de trata de personas en sus distintas colombiana $[y]$ está en un tipo penal complejo" (Henao

"Este estudio aporta a la investigación considerables pautas, desde los elementos que configuran el trabajo forzado, las normas de carácter nacional e internacional que buscan prevenir y erradicar el trabajo forzado, hasta las cifras que se presentan en todo el país sobre los casos del delito de trata de personas en la modalidad de mendicidad ajena en niños, niñas y adolescentes indígenas" (Meertens, 2009). 


\section{Título del documento (tipo)

$\begin{array}{ll}\text { Estudio nacional } & \\ \text { exploratorio } & \\ \text { descriptivo del } & \text { Donny } \\ \text { fenómeno de trata } & \text { Meertens } \\ \text { de personas en } & \\ \text { Colombia (libro) } & \end{array}$

$\begin{array}{ll}\text { Trata de personas } & \text { Elvia } \\ \text { en Colombia: una } & \text { Vargas, } \\ \text { aproximación a } & \text { Carmen } \\ \text { la magnitudy } & \text { Flórez } \\ \text { comprensión del } & \text { y Laura } \\ \text { problema (libro) } & \text { Mendoza }\end{array}$

Es un estudio del fenómeno de trata de personas en todas las regiones del país que identifica la población vulnerable en cada región con relación al desarrollo económico, social, político y cultural, condiciones que inciden en que en cada región varíen las modalidades de trata de personas que se presentan y la población que se ve afectada. Por tal razón, señala las causas por las cuales en ciertas regiones se dan determinadas modalidades de trata, mientras que en otras regiones se desarrollen otras en mayor medida

Contribuye a la investigación teniendo en cuenta que son más los estudios que se han realizado sobre la trata externa de personas, esto es, la que se presenta entre países, que los estudios dedicados a la comprensión de este fenómeno entre las ciudades de un mismo país. Y son más escasos aún los estudios orientados a establecer la relación que existe entre la trata de personas internacional y la nacional.

Sin investigaciones que den cuenta de la realidad del fenómeno de la trata de personas en toda su complejidad, no es posible evaluar el impacto real que han tenido las políticas y programas que se formulan para combatir su ocurrencia.

"La falta de información además dificulta la identificación de buenas prácticas en el ámbito de la trata de personas" (Vargas, Flórez y Mendoza, 2011)

\footnotetext{
El desplazamiento

del embera

chami y su nueva cotidianidad en la ciudad de Pereira: una mirada desde una comunidad indígena asociada con las politicas de desplazamiento (trabajo de grado) Tapasco
}

Contribuye considerablemente en la investigación ya que Luis permite identificar las causas y aspectos que llevan a que Rodrigo los niños, niñas y adolescentes indígenas se vinculen a la mendicidad ajena, las razones por las cuales salen de su resguardo y la manera en que se ejerce la mendicidad (Tapasco, 2008) 


\begin{tabular}{lcl}
$\begin{array}{c}\text { Título del } \\
\text { documento (tipo) }\end{array}$ & Autor & \multicolumn{1}{c}{ Aporte para la investigación } \\
\hline $\begin{array}{l}\text { "Diversidad } \\
\text { cultural y sistema } \\
\text { penal” (artículo) }\end{array}$ & $\begin{array}{l}\text { Juan Carlos } \\
\text { Ferré Olivé }\end{array}$ & $\begin{array}{l}\text { Contribuye a los objetivos específicos de la investigación } \\
\text { porque al tratarse de un grupo étnico, es decir, más } \\
\text { vulnerable y de especial protección, la norma penal debe } \\
\text { ser más rígida al momento de imputar el delito de trata } \\
\text { de personas cuando se cometa en contra de este grupo, } \\
\text { especialmente en niños, niñas y adolescentes indígenas. Pero } \\
\text { a su vez señala que la imputación penal que se realiza para } \\
\text { estos casos de vulneración de derechos fundamentales debe ir } \\
\text { acorde a la jurisdicción ordinaria, respetando la jurisdicción } \\
\text { indígena y en beneficio de garantizar los derechos de los } \\
\text { niños, niñas y adolescentes indígenas (Ferré, 2010) }\end{array}$ \\
\end{tabular}

$\begin{array}{ll}\text { Aspectos juridicos } & \text { Andrea } \\ \text { del delito de trata } & \text { Mateus, } \\ \text { de personas en } & \text { Antonio } \\ \text { Colombia: aportes } & \text { Varón, } \\ \text { desde el derecho } & \text { Beatriz } \\ \text { internacional, } & \text { Londoño, } \\ \text { derecho penal y las } & \text { Beatriz } \\ \text { organizaciones no } & \text { Luna y } \\ \text { gubernamentales } & \text { Mauricio } \\ \text { (libro) } & \text { Vanegas }\end{array}$

Abarca la situación problemática del delito de trata de personas desde el punto de vista penal, desarrollando un marco jurídico-penal, procesal y probatorio, además de casos, normas internacionales y mecanismos de prevención de la trata (Mateus, Varón, Londoño, Luna y Vanegas, 2009)

Fuente: elaboración propia.

\section{Discusión}

El acontecimiento que dio inicio a la aparición del concepto de trata de personas tuvo lugar hace casi dos siglos en Francia, en 1814, cuando se firma el Tratado de París, que establece la obligación de abolir de manera gradual la esclavitud. Téngase en cuenta que la palabra "trata" se refería a la venta de esclavos (Henao, 2008). Este suceso fue el punto de partida para la concepción del delito de trata de personas, al tipificar penalmente, así fuera de manera parcial, una conducta que para la época revestía total normalidad. 
Laura Melissa Álvarez, Laura Daniela Calvo, Gerson Fajardo Guevara Mendicidad ajena como modalidad del delito de trata de personas. Caso embera-chamí

El estudio realizado por Meertens menciona:

En el contexto nacional, la legislación colombiana ha estado acorde con los desarrollos normativos internacionales. Hasta el 2000 la trata de personas se reducía a la explotación sexual y a la trata externa, desconociendo los casos de trata interna y los diversos fines de explotación. (2009, p. 28)

En virtud de lo anterior, la Ley 599 de 2000, "Por medio de la cual se expide el Código Penal", tipifica el delito de trata de personas en sus diferentes modalidades, entre las cuales se encuentra la mendicidad ajena.

Sin embargo, pese a encontrarse tipificada, no existen en la actualidad procesos judiciales activos en torno a dicha conducta delictiva, a pesar de evidenciarse posibles casos que afectan, por ejemplo, a niños, niñas y adolescentes de la comunidad embera-chamí que ejercen actos de mendicidad en las calles de la ciudad de Pereira.

Según Tapasco, dentro de las principales causas que llevan a que los indígenas se desplacen a la ciudad de Pereira se encuentra "la situación de desplazamiento forzado y la emigración por razones económicas y sociales a las que se ha visto sometido en los últimos años el pueblo embera chamí de Risaralda y Caldas" (2008, p. 19).

Sobre lo anterior se han realizado llamados de atención como el del doctor Alexander Granados, exsecretario de Desarrollo Social y Político del municipio de Pereira, quien comunicó que estas familias son reconocidas por ejercer la mendicidad y afirmó que

cada cierto tiempo ellos vienen a la ciudad para pedir dinero en las calles, al parecer los hombres incitan a las mujeres y a los niños a que estos pidan limosna, mientras ellos se quedan en una residencia. Cuando son identificados, solicitan el dinero del pasaje para regresar a sus tierras y a los pocos días de nuevo se les ve en la capital risaraldense. (Granados, 2012)

A pesar de los llamados de atención de la administración municipal, donde se afirma que los padres indígenas son quienes incitan a sus hijos menores a ejercer la mendicidad con el objeto de obtener un beneficio personal, es necesario determinar 
si las causas que están llevando a los indígenas a tal conducta en la ciudad de Pereira se originan en las mismas problemáticas sociales que afectan el territorio indígena generando desplazamiento de la comunidad o si existen meros intereses personales por parte de los familiares en cuestión.

Asimismo, independientemente de las causas o factores que impulsen a los padres indígenas a hacer que sus hijos menores ejerzan la mendicidad, se debe analizar si dicha situación configura el delito de trata de personas, en razón de que los nińos, nińas y adolescentes indígenas son utilizados por terceros como un instrumento para obtener provecho económico.

$\mathrm{Al}$ respecto, Montalván afirma:

La situación donde los niños, niñas o adolescentes se ven obligados a la realización continuadamente de actividades o acciones consistentes en demandas o pedido de dinero en la vía pública, este tipo de maltrato se encuentra muy relacionado con la explotación laboral ya que son asignados a los mismos [sic] con el objeto de obtener un beneficio económico, sin tener que realizar, los adultos, ninguna otra tarea. (2011, p. 24)

La mendicidad ajena como modalidad del delito de trata de personas que afecta a nińos, niñas y adolescentes indígenas debe ser tratada desde dos perspectivas: en primera medida, a la luz de la ley penal colombiana, realizando un desarrollo teórico y jurídico del tipo penal, y en segunda medida, a la luz de la JEI, estableciendo sus características, parámetros y límites para lograr un estudio completo e incluyente de la problemática planteada.

La trata de personas puede ser concebida desde diferentes enfoques. Existen concepciones enfocadas en el aspecto sociológico, como la de Giraldo, que define la trata de personas como "una categoría del tráfico humano en la cual se degrada al ser humano a la condición de un objeto” (2008, p. 17).

Otras posturas son mucho más radicales, como las planteadas en los diferentes modelos normativos que se concentran en la trata de personas como delito y se 
Laura Melissa Álvarez, Laura Daniela Calvo, Gerson Fajardo Guevara

clasifican en prohibicionista, abolicionista, reglamentarista y legalista (Saidiza y Carvajal, 2016). De acuerdo a esta clasificación Barrera y Moreno explican algunas teorías con respecto a la trata de personas, no sin antes advertir que el Instituto Colombiano de Bienestar Familiar (ICBF) ha buscado regular las situaciones de discriminación y maltrato a la población infantil y hacer frente a la irresponsabilidad familiar, la deficiencia nutricional, la pérdida de valores y la niñez abandonada, entre otras problemáticas como la relacionada en las presentes líneas (Barrera y Moreno, 2018).

\section{Enfoque prohibicionista}

Este modelo se fundamenta en que el trabajo sexual atenta contra los principios expuestos en los derechos humanos, por lo que se deben tomar acciones legales contra quienes se dedican a esta actividad. Este modelo contiene una visión que se podría denominar moralista, que defiende la moral pública y las buenas costumbres. (Laverde, 2015, p. 42)

Este modelo se concibe desde una perspectiva moralista, según la cual quien ejerce la labor sexual se asemeja a un delincuente. Visto desde esta teoría, el cliente es simplemente un sujeto exento de responsabilidad penal. Con fundamento en lo anterior, Laverde manifiesta: "Se asume que la conducta delictiva recae exclusivamente sobre quien presta el servicio sexual” (2015, p. 43).

\section{Enfoque abolicionista}

Al contrario de la teoría prohibicionista, la abolicionalista se define como

una corriente jurídica en la que el trabajo sexual no puede darse de forma voluntaria, por lo que el uso del cuerpo para la prestación de servicios sexuales representa una forma de explotación por quienes manejan el negocio, lo que significa un atentado contra sus derechos humanos. (Laverde, 2015, p. 44)

Es así como esta teoría expresa que quien es explotado sexualmente debe ser considerado víctima, debido a la grave vulneración de los derechos humanos que 
sufre. "Por su parte, Pablo de Lora sostiene que los Estados que mantienen un modelo abolicionista, conciben la prostitución como una 'actividad básicamente degradante e indigna; antes bien, deben dirigir sus esfuerzos en pos de su desaparición'” (Barrera y Moreno, 2018).

Tirado explica:

El modelo abolicionista elimina no el hecho en sí de la prostitución, sino la aceptación de su existencia y, por tanto, de regulación normativa. Se fundamenta en la protección de la familia y de las mujeres. De tal manera que excluye la punición de la actividad individual; sin embargo, persigue su entorno, es decir, la organización de negocios en cuanto a la prestación de servicios sexuales. (2011, p. 139; segundo énfasis añadido)

Este modelo normativo busca que se garantice el derecho fundamental a la dignidad humana (Guarín y Aldana, 2016), de la cual gozan todos los seres humanos, y por lo tanto no concibe la posibilidad del ejercicio legal de la venta de servicios sexuales, que considera degradante de los derechos humanos y necesariamente vulnerador de los derechos de las víctimas.

\section{Enfoque reglamentarista}

Laverde explica este modelo normativo así: "El modelo reglamentarista define implícitamente una distinción entre la prostitución libre y la forzada, lo que permite diferenciar y dimensionar problemáticas como el tráfico y la explotación sexual" (2015, p. 44).

A diferencia de los anteriores modelos, este reconoce que puede hacerse una distinción entre la prostitución como una actividad voluntaria y la prostitución referida al delito de trata de personas en la modalidad de explotación sexual, que debe ser totalmente rechazada. 
Por lo anterior, este modelo concibe la posibilidad de regular la prostitución ejercida de manera voluntaria, para fines de sanidad y prevención de enfermedades de transmisión sexual (ETS), entre otros.

Es así como Laverde establece:

Desde esta corriente se concibe a la prostitución como un mal menor y necesario, por lo que se reconoce su existencia con la protección en temas como la salud y el establecimiento de zonas especiales en las que se pueda controlar y vigilar el orden público. De acuerdo a la organización en zonas delimitadas para el ejercicio del trabajo sexual, las pretensiones no son de protección a la libertad personal sino de control de un mal que puede derivar en aumento de problemas sociales como las ETS. Se establecen medidas para que quien ejerce el trabajo sexual asista periódicamente a controles sanitarios para así evitar problemas de salud pública. (2015, p. 45)

Asimismo, Tirado explica:

El modelo reglamentista reconoce la prostitución como un mal social que, al no poderse combatir, debe ser regulado frente a los efectos perniciosos relacionados con la salud, la convivencia y las buenas costumbres; es decir, que este modelo pretende cuidar al cliente y, de forma indirecta, a aquellos que viven la prostitución sin ejercerla, pues permite la explotación de establecimientos comerciales relacionados con esta actividad sexual y se facilita el contacto entre trabajador o trabajadora sexual y clientes. (2011, p. 139)

\section{Enfoque legalista}

Laverde expresa: "En el marco de la concepción laboral, se busca reconocer derechos que van desde el acceso a la salud hasta el cumplimiento de un horario, el derecho a sindicalizarse, aportes para jubilación, [...] entre otros" (2015, p. 46). 
Este modelo busca el reconocimiento de derechos de quienes ejercen el trabajo sexual, bajo el entendido de unas garantías laborales que les permitan acceder a todas las prestaciones vigentes, como salud, pensión y demás derechos inherentes a quienes realizan actividades laborales, aunque para este caso en concreto se trate de trabajo sexual: "El modelo que busca la legalización del trabajo sexual va en contravía del modelo abolicionista o reglamentarista, sustentado en la libertad del individuo que suele ser cohibida por las concepciones moralistas" (Laverde, 2015, p. 46).

Este modelo choca con los mencionados anteriormente porque en estos la prostitución es invariablemente incluida dentro del delito de trata de personas en la modalidad de explotación sexual, y por lo tanto es rechazada de plano.

La trata de personas puede tener diferentes fines entre los cuales se destacan la explotación sexual y el trabajo forzado. Se ha abordado la primera con mayor profundidad. Sin embargo, el segundo es un fenómeno que parece adquirir cada vez más fuerza a nivel mundial y tiene como víctimas mayoritarias a menores de edad.

Teniendo en cuenta la posibilidad de judicialización, cabe evaluar esta a la luz del caso embera-chamí pues, como se ha consagrado en el artículo 7 de la Constitución Política de Colombia, "el Estado reconoce y protege la diversidad étnica y cultural de la nación colombiana”. Frente a esto, Mora manifiesta:

Estrechamente vinculado al derecho a la identidad cultural, que tiene su expresión en el carácter pluriétnico y multicultural de la nación colombiana, se encuentra el derecho a la autonomía, que se traduce en la posibilidad de autodeterminarse como pueblo, es decir, de establecer su propia organización, sus características formas de gobierno, sus específicas estructuras sociales, administrativas, económicas conforme a sus usos y costumbres, así mismo de tener sus propias autoridades tradicionales, de guiarse bajo sus propias normas y códigos de comportamiento. (2003, p. 55)

El componente principal del concepto de trata de personas es la finalidad de explotación sin que se exija su consumación porque es allí donde está la máxima vulneración del derecho fundamental de la dignidad humana, intrínseco a todos los 
Laura Melissa Álvarez, Laura Daniela Calvo, Gerson Fajardo Guevara

seres humanos en razón de su condición como tales (Guarín, 2015). Transgredir ese derecho fundamental tratando a una persona como "mercancía" es la posición más denigrante en la que se puede poner a un ser humano. Por eso la trata es un tema de alarma para todas las entidades gubernamentales y no gubernamentales del mundo.

Lo anterior se plantea para entender que el concepto de mendicidad ajena referida a niños, niñas y adolescentes indígenas debe verse desde tres puntos de vista:

Primero, el individual. La mendicidad ajena interfiere con la dignidad, la libertad, el libre desarrollo de la personalidad, etc., y más aún, vulnera de manera inminente la condición especial del menor indígena, ya que al ser de una cultura de especial protección constitucional debe dársele un trato digno y diferente. Por tal razón la trata de personas en su modalidad de mendicidad ajena afecta evidentemente la condición especial de dicho grupo poblacional.

Segundo, el social. La mendicidad es un factor que genera rechazo social y malestar entre los habitantes de la ciudad de Pereira, porque los indígenas tienen sus resguardos dentro de su jurisdicción especial y ejercer la mendicidad fuera de esta no es ni social ni jurídicamente aceptable y se resume en un alto grado de discriminación.

Tercero, el jurídico. Dentro de la jurisdicción penal ordinaria la mendicidad ajena se considera una modalidad del delito de trata de personas (Forero, 2014). Por tal razón no es jurídicamente permitido que las comunidades indígenas se desplacen de sus resguardos y se dirijan a la ciudad de Pereira a ejercer esa práctica, cuya víctima es el menor indígena.

Cuestión aparte son los diversos factores que podrían influir en la dificultad de prevenir y judicializar este delito en la jurisdicción ordinaria: "El requerimiento de la denuncia del delito cuando por ley opera la investigación oficiosa; la necesidad de llevar a la víctima al juicio como testigo y la aceptación cultural a comportamientos que constituyen trata de personas" (Henao, 2008, p. 395). Cuando esta conducta se presenta en indígenas se debe sumar la complejidad propia de la protección especial de la que gozan estas comunidades, inherente a su autonomía de conformidad con los artículos 7 y 246 de la Constitución Política de Colombia. 
Al existir un reconocimiento constitucional de las comunidades indígenas que garantiza la protección de sus culturas, se les concede autonomía. De esta manera, surge para ellos la posibilidad de crear su propia jurisdicción, que goza de protección especial. Al respecto, señala Rodríguez:

Precisamente, el llamado multiculturalismo ha supuesto nuevos desafíos para el derecho penal, pues la valoración que puede tener un determinado comportamiento variará conforme el contexto cultural al que pertenezca el autor. Para precisar cuál es el alcance del multiculturalismo y cómo debe enfrentarlo el derecho penal, es indispensable examinar aquellas tesis que se dirigen a resolver los problemas propios de la diversidad cultural, a saber, las liberales y las comunitaristas. Lo anterior permitirá comprender qué se entiende por delitos culturalmente motivados y si la respuesta, para su tratamiento penal, debe hallarse en la esfera de la antijuridicidad o en la culpabilidad. (2007, p. 45)

De esta manera nace la JEI, que tiene como principal objetivo proteger la diversidad étnica, otorgando a dichas comunidades herramientas de autodeterminación, entre las cuales se encuentra la creación y aplicación de sus propias leyes bajo el dominio de sus propias autoridades.

Por lo anterior, a pesar del llamado de atención del doctor Alexander Granados (exsecretario de Desarrollo Social) los niños, niñas y adolescentes indígenas siguen en las calles de Pereira ejerciendo la mendicidad. Técnicamente, se encuentran fuera de su resguardo indígena y bajo la aparente aplicación de la jurisdicción ordinaria.

Así pues, ¿cuáles han sido las acciones desplegadas para determinar si efectivamente se está en presencia del delito de trata de personas en la modalidad de mendicidad ajena? Y en el evento de que la respuesta sea positiva, ¿qué posibilidad existe, desde la perspectiva de la imputación penal, de judicializar dicha conducta teniendo en cuenta que sus actores son integrantes de una comunidad indígena? 
Laura Melissa Álvarez, Laura Daniela Calvo, Gerson Fajardo Guevara

\section{Resultados}

- La mendicidad a la que son sometidos los niños, nińas y adolescentes indígenas de la comunidad embera-chamí (Risaralda) tiene su origen en ciertas condiciones sociales, económicas, de orden público, de presión territorial y de acceso limitado a recursos básicos para subsistir en territorio ancestral, sumadas al conflicto armado y las acciones de las fuerzas del Estado en ese sentido. Todo eso propició el desplazamiento de dicha comunidad a diversas zonas del país.

- Lo señalado anteriormente se resume en factores de violencia y desplazamiento como principales causas por las cuales los niños, niñas y adolescentes indígenas de la comunidad embera-chamí son vinculados al ejercicio de la mendicidad ajena como modalidad del delito de trata de personas.

- Otra afectación que sufren estas comunidades es el acceso restringido a los programas asistenciales de entes territoriales y organizaciones no gubernamentales.

- Se hace claridad en que, tal como lo expresó el director regional de la Unidad de Atención para las Víctimas del Eje Cafetero, la práctica de la mendicidad está prohibida por parte de las autoridades indígenas embera, so pena de aplicar uno de sus castigos tradicionales.

- Es una problemática cultural puesto que se sustraen grupos familiares de los lugares donde están sus prácticas tradicionales y son arrojados a condiciones ambientales y culturales distintas, sin tener acceso a una infraestructura en salud que se adapte a sus condiciones o a una educación sicosocial adecuada para sus menores.

- Por parte del ICBF existe un trámite administrativo que busca la protección y el restablecimiento de los derechos de los niños, niñas y adolescentes indígenas, y un procedimiento especial para adelantar dicho trámite. Asimismo, el ICBF reconoce que efectivamente existen problemáticas asociadas a la mendicidad 
entre la población embera, y para esto diseñó una ruta de atención de los niños y niñas de esa comunidad inmersos en esa práctica, cuyos derechos se encuentran amenazados, inobservados o vulnerados.

- La Secretaría de Desarrollo Social del departamento de Risaralda es consciente de la práctica denunciada y por tal razón está desarrollando una política pública al respecto en las administraciones municipales de Pereira y Dosquebradas.

- Cuando la administración evidencia situaciones de ese tipo, se las comunica al Consejo Regional Indígena para que tome medidas al respecto, sin que haya intermediación de entidades diferentes, a excepción de los casos en los que interviene el ICBF por tratarse de menores.

- Funcionarios del Ministerio de Interior expresan que efectivamente en dicha entidad han tenido conocimiento de situaciones de mendicidad ajena por parte de la comunidad embera-chamí, de conformidad con los informes recibidos por la Gobernación del Departamento de Risaralda. Atribuyen dichas situaciones al conflicto armado, a conflictos intra e interétnicos y al atractivo que ofrece la urbe.

- Actualmente no existe política pública que se esté implementando para prevenir y contrarrestar la mendicidad ajena como modalidad del delito de trata de personas en niños, niñas y adolescentes indígenas, pero como se mencionó anteriormente, se encuentra en elaboración por parte de la Gobernación del Departamento de Risaralda.

- Todos los funcionarios reconocen la presencia de miembros de la comunidad embera-chamí en las calles de la ciudad de Pereira y el ejercicio de la mendicidad por parte de los niños, niñas y adolescentes de tal comunidad. A pesar de lo evidente de estos casos, ninguno actualmente ha sido judicializado.

- A pesar de las reuniones con el Consejo Regional Indígena solicitando que se intervenga en esta situación, y de que sus directivas se comprometieran a 
Laura Melissa Álvarez, Laura Daniela Calvo, Gerson Fajardo Guevara Mendicidad ajena como modalidad del delito de trata de personas. Caso embera-chamí

establecer controles, el procedimiento a seguir es que cuando se identifican estos casos se deben reportar a esta organización y sus directivas establecen las medidas de castigo y juzgamiento correspondientes. Excepcionalmente interviene el ICBF cuando son casos graves de vulneración de derechos fundamentales de menores.

- Existen funcionarios que a pesar de no tener conocimiento de algún caso particular de dicha problemática en su ejercicio profesional, sí han visto en las calles de la ciudad mujeres y niños indígenas pidiendo limosna. La situación, dicho sea de paso, se presenta en diferentes municipios.

- La Fiscalía General de la Nación manifiesta que se han adelantado operativos por parte de la Secretaría de Desarrollo Social y Político de Pereira para reubicar a los miembros de la comunidad embera-chamí, en vista de que la misma comunidad ha comunicado que algunas de sus familias son reconocidas por ejercer la mendicidad. Los datos de estas personas ya fueron ingresados a la Unidad de Atención y Orientación para Desplazados (UAO), pero las solicitudes fueron rechazadas por encontrar presuntas anomalías en las historias que aquellas cuentan a las autoridades.

- A pesar de que los servidores públicos y las personas que trabajan con víctimas (Unidad de Atención y Reparación para las Víctimas) han visto e identificado las prácticas de mendicidad ajena aquí expuestas, hasta la fecha no se han radicado denuncias formales en la Fiscalía, en las cuales se presenten casos de mendicidad ajena como modalidad del delito de trata de personas en niños, niñas y adolescentes de la comunidad embera-chamí, tal como lo reportó la Fiscalía General de la Nación-Seccional Risaralda.

- Es una práctica que a pesar de haber sido visibilizada, no ha trascendido al ámbito legal.

- La sentencia T-002/2012, proferida por la Corte Constitucional, reconoce el carácter constitucional de la JEI. En tal sentencia se definen aspectos fundamentales sobre las competencias de dicha jurisdicción, que buscan 
garantizar que las comunidades indígenas cuenten con el apoyo de las autoridades y con procedimientos judiciales bien definidos para poder ejercer su autonomía, aún en ausencia de una ley de coordinación, sin perder de vista que el sometimiento de la JEI a la Constitución Política y la ley debe conectarse armónicamente con los límites propios de la autonomía de los pueblos en tanto derecho fundamental.

- La Corte Constitucional determinó cuatro elementos fundamentales que delimitan el ejercicio de la JEI: 1) la existencia de autoridades judiciales propias de los pueblos indígenas, 2) la potestad de establecer normas y procedimientos propios, 3) la sujeción de dicha jurisdicción y de tales normas a la Constitución y la ley, 4) la competencia del legislador para señalar la forma de coordinación de la jurisdicción indígena con el sistema judicial nacional.

- Todos los servidores públicos tienen conocimiento de la jurisdicción indígena, sus límites y alcances, y reconocen que dicha institución goza de rango constitucional y permite a las comunidades indígenas autodeterminarse, según el artículo 267 de la Constitución Política de 1991.

- No existen evidencias para determinar si son directamente los padres indígenas quienes imponen el ejercicio de la mendicidad ajena a sus hijos o si por el contrario las redes de trata de personas están vulnerando a esta población.

- Se presentan una serie de falencias normativas e interpretativas que impiden a los operadores judiciales realizar una correcta interpretación y determinación al momento de establecer qué jurisdicción es la encargada de asumir el conocimiento de posibles casos en los cuales sea un miembro de una comunidad indígena el que ejecute una conducta delictiva.

- Atendiendo a lo dispuesto por la Carta Política, la Corte Constitucional es la encargada de resolver los conflictos de competencia jurisdiccional entre la JEI y la jurisdicción ordinaria. 
Laura Melissa Álvarez, Laura Daniela Calvo, Gerson Fajardo Guevara Mendicidad ajena como modalidad del delito de trata de personas. Caso embera-chamí

- Son elementos de los límites de la JEI: su carácter territorial, cultural, los bienes jurídicos afectados, los procedimientos, la autoridad capacitada, la institucionalidad y las normas relacionadas con el delito, ya que la conducta cometida debe entenderse como lesiva de un bien jurídico en las dos jurisdicciones.

- En principio los miembros de comunidades indígenas que cometan conductas delictivas sí deben ser judicializados por la jurisdicción ordinaria, siempre y cuando cometan delitos por fuera de los límites de la JEI señalados anteriormente, porque en principio al ser la ciudad de Pereira el casco urbano haría pensar que correspondería a la jurisdicción ordinaria. No obstante, el factor territorial por sí solo se puede desbordar, en caso de que sean los propios embera quienes cometan el delito bajo los usos y costumbres indígenas y además la autoridad indígena correspondiente conciba como delito la conducta cometida.

- Es necesario, de conformidad con los aspectos de competencia planteados y los criterios para definir si es posible o no que la jurisdicción ordinaria conozca de delitos cometidos por miembros de comunidades indígenas, verificar el papel del derecho penal en estos casos y el acompañamiento o manejo que debe dársele al asunto puesto en consideración en la hipótesis. Esto debido a que en principio se trata de asuntos propios de una jurisdicción especial consagrada y protegida constitucionalmente.

- Existe no solo tensión, sino también desconocimiento de los alcances y límites de la JEI. Muchas autoridades indígenas tienen la percepción de que su fuero o su jurisdicción especial son para autorizarlos a cometer cualquier tipo de actos, desconociendo que las comunidades indígenas deben acatar la Constitución Política de Colombia.

- Es por esta razón que todos los operadores judiciales coinciden en que, si bien los miembros de comunidades indígenas gozan de protección constitucional frente al reconocimiento de su jurisdicción especial, y que por lo tanto deben ser juzgados por sus propias autoridades indígenas, también es cierto que en 
caso de vulnerar los límites de tal jurisdicción quedan sujetos a ser juzgados por la justicia penal ordinaria. En dichos casos inicialmente el juez penal debe valorar si el comportamiento del miembro de la comunidad indígena obedeció a un error invencible de prohibición, originado en su cosmovisión. Si sí, deberá remitirlo a la JEI; si no, seguirá conociendo del asunto.

- Se debe aclarar que la mendicidad por sí sola no es un delito, lo que configura el delito de la mendicidad ajena es la utilización de un ser humano en la figura de la mendicidad en beneficio de un tercero. Quizás esto no existe para la comunidad embera-chamí, y simplemente el indígena debe ser tomado como víctima de explotación de trata de personas. No existe claridad en la aplicación de la jurisdicción, hay temor entre los funcionarios de incurrir en prevaricato.

- En resumen, hay que tener claros los criterios establecidos por la Corte Constitucional para determinar qué jurisdicción tiene conocimiento al momento de judicializar indígenas. Asimismo, hay que saber reconocer las implicaciones de la diversidad cultural y el papel que tiene el derecho penal en el tema. Es necesario analizar cada caso en concreto y determinar el nivel de arraigo cultural del indígena, al igual que su capacidad de comprensión de la sociedad.

- Asimismo se debe analizar a qué cultura está afectando el indígena cuando vulnera un bien jurídico y el grado de lesividad de su acción.

\section{Conclusiones}

La trata de personas en la modalidad de mendicidad ajena es ejercida por los padres indígenas de la comunidad embera-chamí sobre sus hijos, que salen de sus resguardos abandonando su jurisdicción indígena y se desplazan a las ciudades, donde configuran la conducta punible del tipo penal referido. Dicha conducta es sancionada por la jurisdicción penal ordinaria y se encuentra contemplada en la legislación penal colombiana. 
Laura Melissa Álvarez, Laura Daniela Calvo, Gerson Fajardo Guevara Mendicidad ajena como modalidad del delito de trata de personas. Caso embera-chamí

Pese a la concreción del delito de trata de personas en la modalidad de mendicidad ajena, no se puede judicializar dicha conducta punible por la protección constitucional de la cual gozan las comunidades indígenas. Es así como la Corte Constitucional prohíbe que los individuos de tales comunidades sean judicializados por la jurisdicción ordinaria, y por el contrario exige que sean reintegrados a su cultura, independientemente de su arraigo cultural, dentro de los fines constitucionales señalados respecto de la protección y garantía de los derechos de las minorías étnicas.

En la mayoría de los casos los operadores judiciales se abstienen de juzgar a los indígenas, toda vez que no existe claridad sobre los límites y alcances de la JEI y el ámbito de aplicación de la jurisdicción ordinaria para comunidades indígenas.

La mendicidad ajena se debe judicializar con el solo hecho de ver que el niño la ejerce. La labor de las comunidades debe ser mucho más proactiva en ese sentido: identificar los posibles casos de trata antes de que se lleguen a consumar.

\section{REFERENCIAS}

Alcaldía de Pereira (2017). Pereira. Capital del Eje. Recuperado de https://goo.gl/5SLPeh

Barrera, J. y Moreno, M. (2018). La persona en el grado civil. Crítica a la realidad del proceso de adopción y no adopción de adolescentes. Via Inveniendi et Iudicandi, 13(1), 119-140. Doi: http://dx.doi.org/10.15332/s1909-0528.2018.0001.04

Castro, G, (2018). Una aproximación teórica a la obra de Arturo Valencia Zea De la posesión y la función social de la propiedad: el gran problema jurídico del siglo XX en Colombia, revisión histórico jurídica. Via Inveniendi et Iudicandi, 13(1), 9-54. Doi: http://dx.doi. org/10.15332/ s1909-0528.2018.0001.01

Ferré, J. C. (2010). Diversidad cultural y sistema penal. Revista Digital de la Maestría en Ciencias Penales de la Universidad de Costa Rica, 2. 
Forero, J. (2014). El valor superior de la justicia en la Unión Europea. Especial referencia al Estado constitucional social y democrático de derecho español. Verba Iuris, 31, 91-114.

Giraldo, V. E. (dir.) (2008). Metamorfosis de la esclavitud. Manual jurídico sobre trata de personas. Bogotá: Fundación Esperanza.

Granados, A. (13 de julio de 2012). Noticias de impacto en Pereira. Diario del Otún.

Guarín, E. (2015). Una aproximación filosófico-jurídica al sentido de la expresión: "Realización efectiva de los derechos”. Verba Iuris, 34, 147-159.

Guarín, E. A. y Aldana, J. (2016). Estado jurisdiccional y bien común. Verba Iuris, 11(36), $13-26$.

Henao, M. I. (2008). Lucha contra la trata de personas: desafío para Colombia en el siglo XXI. Revista Criminalidad, 50(1). Recuperado de https://goo.gl/Ac6ewH

Huertas, O., Leyva, M., Lugo, L., Perdomo, W. y Silvero, A. (2016). Entre la minimización y la expansión del derecho penal: la presencia de Beccaria en el debate contemporáneo. Revista Iusta, 1(44), 41-59. Recuperado de https://goo.gl/ayfGB5

Manzo, G. A. (2018). Análisis comparado de una sentencia relativa al Estado social de derecho del Tribunal Supremo de Justicia venezolano (TSJ) y la Corte Constitucional Colombiana (CCC). Verba Iuris, 13(40), 175-187.

Mateus, A., Varón, A., Londoño, B., Luna, B. y Vanegas, M. (2009). Aspectos jurídicos del delito de trata de personas en Colombia: aportes desde el derecho internacional, derecho penal y las organizaciones no gubernamentales. Bogotá: Ministerio del Interior y de Justicia / UNODC/ Universidad del Rosario.

Meertens, D. (2009). Estudio nacional exploratorio descriptivo sobre el fenómeno de trata de personas en Colombia. Bogotá: Universidad Nacional de Colombia /UNODC/ Ministerio del Interior y de Justicia. 
Ministerio de Cultura, República de Colombia (2010). Embera Katío. Recuperado de http://www.mincultura.gov.co/areas/poblaciones/noticias/Documents/Caracterizaci\% $\mathrm{C} 3 \% \mathrm{~B} 3 \mathrm{n}$

Molina, Y. (2016). Derecho penal del enemigo y dignidad humana. Verba Iuris, 11(36), $135-146$.

Montalván, P. A. (2011). La prevención de la mendicidad de niños, niñas y adolescentes como problema social y juridico en el Ecuador (trabajo de grado). Universidad Nacional de Loja, Ecuador.

Mora, D. F. (2003). Bases conceptuales de la jurisdicción especial indígena (trabajo de grado). Pontificia Universidad Javeriana, Bogotá.

Murcia, T. (2018). La crisis del financiamiento del Sistema Interamericano de Derechos Humanos: una amenaza a la protección de derechos humanos en América. Verba Iuris, 13(39), 49-66.

OIM (Organización Internacional para las Migraciones) (2017). Organización Internacional para las Migraciones. Recuperado de http://www.oim.org.co/

Quiroz, M. (2014). Acercamiento a las “oposiciones paradigmáticas” entre neoconstitucionalismo y positivismo jurídico. Revista Iusta, 2(41), 77-97. Recuperado de https://goo. $\mathrm{gl} / \mathrm{wvZZgr}$

República de Colombia (1992). Constitución Politica de Colombia.

Rodríguez, R. C. (2007). El multiculturalismo: un desafío para el derecho penal moderno. Politica Criminal, 2(3). Recuperado de http://www.politicacriminal.cl/n_03/a_6_3.pdf

Saidiza, H. y Carvajal, J. (2016). Crisis del Estado de derecho en Colombia: un análisis desde la perspectiva de la legislación penal. Revista Iusta, 1(44), 17-39. Recuperado de https:// goo.gl/TM8D3q 
Tapasco, L. R. (2008). El desplazamiento del embera chami y su nueva cotidianidad en la ciudad de Pereira: una mirada desde una comunidad indígena asociada con las politicas de desplazamiento (trabajo de grado). Universidad Tecnológica de Pereira, Pereira.

Vargas, E., Flórez, C. E. y Mendoza, L. M. (2011). Trata de personas en Colombia: una aproximación a la magnitud y comprensión del problema. Bogotá: OIM / Uniandes. 